\title{
Reply by the author to the comment on the paper 'Towards a rational definition of potential evaporation' by J.P. Lhomme
}

If I understand well the rationale of the authors of this comment, the term 'potential evaporation' (denoted by $E_{p}$ ) does not need a precise definition because no definition can be truly satisfactory to everyone, the concept being inexact and its interpretation depending essentially on context. For the authors, this term conveys a common understanding of an upper limit to evaporation in a given environment and is useful only as a conceptual tool. Therefore it 'should be retained for those occasions when the precision offered by a definition is not required'.

Firstly, I do not think the concept of potential evaporation is inexact. A concept is a mental representation of the real world and apparently we agree on what the concept of potential evaporation means: the upper limit of evaporation in a given environment. Neither do I share the idea that the understanding of potential evaporation is not aided by precise definition. It is not impossible and fruitless to find a common ground between those involved in different fields (hydrology, meteorology, agricultural science, etc.) to define what is meant by potential evaporation. On the contrary, it is necessary to bridge the gap between these disciplines and to share a common understanding. A vague and ill-defined concept is always the source of misunderstanding and benefits nobody. My paper shows that $E_{p}$ can be defined precisely while conveying the common understanding of an upper limit to evaporation. These two aspects are not incompatible at all. The concept of field capacity in soil science (taken as a comparison by the authors) conveys the general idea of the amount of water remaining in the soil after the loss of water by gravity. This amount is highly variable because it depends upon soil characteristics. Nevertheless, it can be defined accurately by fixing the corresponding value of soil water potential $(p F=2.8)$.

Contrary to what the authors say, the definition proposed for potential evaporation (wet surface evaporation in their terminology) covers a wide range of situations since it applies to any type of surface from open water to a highly heterogeneous terrain; it is applicable whatever the characteristics of the surface (albedo, roughness length, soil heat flux, etc.). I admit, however, that for heteroge- neous surfaces the calculation could be a little tricky because the appropriate aggregation rules needed to calculate the aggregate parameters are not known with complete certitude. But the problem is solved if these aggregate characteristics can be measured directly. The main drawback encountered by the definition proposed is its physical significance or interpretation. This issue has been examined thoroughly in the paper and it has been shown that this drawback also exists for the other definitions such as reference crop evaporation.

On the basis of their main argument (potential evaporation should not be defined precisely), the authors propose a series of names for different types of evaporation related to the general concept of potential evaporation and 'useful under the circumstances for which they were developed': Penman evaporation (Penman, 1948), reference crop evaporation (Doorenbos and Pruitt, 1977), reference transpiration (Allen et al., 1994), Priestley-Taylor evaporation (Priestley and Taylor, 1972), wet surface evaporation, open water evaporation. I have no objection against such a list of specific evaporations which can be extended again and used independently of the concept of $E_{p}$. I have to point out, however, that the difference between 'reference crop evaporation' and 'reference transpiration' is not clear for me; what is called 'reference transpiration' by the authors is defined as 'reference crop evaporation' by Shuttleworth (1993). Anyhow, such a list of specific evaporations does not solve the problem of defining potential evaporation. Moreover, it will increase the confusion if all these evaporations are granted the name of potential evaporation by their respective users.

Among the possible 'candidates' for the title of 'potential evaporation', $I$ think it is possible to determine in a strictly rational way which one is the most suitable; and this issue was essentially the purpose of my paper. I have shown that reference crop evaporation (or reference transpiration) does not represent stricto sensu an upper limit to evaporation in a given environment because it corresponds to a surface resistance different from zero in the PenmanMonteith equation (Monteith, 1965). The Priestley-Taylor evaporation is not a good candidate either, since its empir- 
ical coefficient $\alpha(=1.26$ in the original formulation) can vary as a function of the type of climate (Shuttleworth, 1993). From my point of view, only the wet surface evaporation, which includes in fact Penman evaporation and open water evaporation, really deserves the name of potential evaporation.

\section{References}

Allen, R.G., Smith, M., Pereira, L.S. and Perrier, A. 1994. An update for the calculation of reference evapotranspiration. ICID Bulletin, 43(2), 35-92.
Doorenbos, J. and Pruitt, W.O. 1977. Guidelines for predicting crop water requirements. FAO Irrigation and Drainage Paper No 24, 2nd edition, 156 pp.

Monteith, J.L. 1965. Evaporation and the environment. Symp. Soc. Exp. Biol., 19, 205-234.

Penman, H.L. 1948. Natural evaporation from open water, bare soil and grass. Proc. Roy. Soc. Lond. A, 193, 120.145.

Priestley, C.H.B, and Taylor, R.J. 1972. On the assessment of surface heat flux and evaporation using large scale parameters. Mon. Weather Rev., 100, 81-92.

Shuttleworth, W.J. 1993. Evaporation. In: D.R. Maidment (Editor), Handbook of Hydrology. McGraw-Hill, New York. pp. 4.1-4.53. 